\title{
МОДЕЛИРОВАНИЕ СБАЛАНСИРОВАННОГО КРЕДИТНОГО ПОРТФЕЛЯ КОММЕРЧЕСКОГО БАНКА В УСЛОВИЯХ НЕДРУЖЕСТВЕННОЙ СРЕДЫ
}

\author{
Н. Б. Баева, В. Н. Тычинина \\ Воронежский государственный университет
}

Поступила в редакцию 12.02.2018 г.

\begin{abstract}
Аннотация. В статье рассмотрено основное направление деятельности современных коммерческих банков - выдача кредитов, являющееся как доходной, так и рискованной операцией. Выдавая кредиты, банк непосредственно формирует свой кредитный портфель. В работе описывается проблема управления кредитным портфелем коммерческого банка в условиях недружественной среды с учетом предотвращения или минимизации кредитного риска. Предложена модель формирования оптимального кредитного портфеля коммерческого банка, возможности использования которой оценены на основе экспериментальных расчетов, проведенных с помощью исходных данных одного из банков Воронежской области.

Ключевые слова: кредит, портфель, коммерция, управление, коммерческий банк.

Annotation. The work considers the issue of managing the loan portfolio of a business bank under present day conditions aiming to prevent or minimize risk. The model of forming the optimal investment portfolio of a commercial Bank is proposed. The possibilities of its use are estimated on the basis of experimental calculations, given in an unfriendly environment and using the initial data of one of the banks of the Voronezh Region. The main line of activity of modern commercial banks is considered - the issuance of loans, which is both profitable and risky operation. Issuing loans, the bank directly forms its loan portfolio.

Keywords: loan, portfolio, commerce, manage-ment, commercial bank.
\end{abstract}

\section{ВВЕДЕНИЕ}

Глобальный финансовый кризис проявляется в настоящее время в дестабилизации экономик стран, в росте стоимости денежных средств, в сокращении предложения коммерческими банками в сфере использования их средств в течение длительного периода. Внешняя среда банков становится недружественной. Это усиливает роль рискообразующих факторов, и вызывает необходимость переоценки уровня системного риска. В этих условиях возрастает актуальность исследовательских работ в области анализа эффективной банковской деятельности. Целью деятельности коммерческого банка является удовлетворение желаний потенциальных и существующих клиентов, от которых будет зависеть его положение на финансовом рынке.

() Баева Н. Б., Тычинина В. Н., 2018
В данной работе рассмотрена модель банка, как системы, а также предложены способы проверки совокупности финансовых операций на системность, то есть, предложена методика особого комплекта банковских продуктов, при которых работа банка становится более эффективной.

\section{1. БАНК КАК СТРУКТУРИРОВАННАЯ СИСТЕМА}

Основоположником теории систем является Людвиг фон Берталанфи, который определял «систему как комплекс взаимодействующих элементов или как совокупность элементов, находящихся в определенных отношениях друг с другом и со средой». А. Холл понимал под системой «множество предметов вместе со связями между предметами и между их признаками». Начиная с основоположника кибернетики У. Р. Эшби в определе- 
ние понятия «система» наряду с элементами, связями и их свойствами, и целями начинают включать наблюдателя.

С нашей точки зрения наиболее точным является определение системы, введенное Л. Г. Гранбергом [1]:

Системой $(S)$ называется совокупность элементов, взаимосвязанных между собой и обладающих целостностью и единством. Система состоит из элементов, подсистем и связей [2].

Система описана как структурированная и представляется в виде:

$$
S_{u c x}=\langle(e, E),(r, R), C m(E, R)\rangle .
$$

Важное значение в описании имеет её структурное представление и связь с окружающей средой.

Основные оценки факторов внешней среды приведены в работе [3]. Опираясь на эти положения, приведем структуру о внешней среде банка (рис. 1).

- микросреда реализуется в виде анализа влияния на деятельность коммерческого банка и его конкурентоспособность, клиентов, в качестве которых выступают физические, юридические лица, индивидуальные предприниматели и др.
- макросреда (воздействие на деятельность банка слагается из его отношений с силами, составляющими внешнюю среду),

- конкурентное окружение (оценка уровня конкурентной борьбы на рынке банковских услуг).

Экономическое положение физических лиц, юридических лиц, индивидуальные предприниматели и других возможных заёмщиков банка в значительной степени определяются состоянием внешней среды, под которым мы понимаем политические, экономические, социальные и другие основные характеристики среды.

Основными характеристиками внешней среды, в нашем понимании, являются взаимосвязанность, сложность, подвижность, неопределенность действий многих факторов. Оптимальное состояние коммерческого банка зависит от того, в каком состоянии находится внешняя среда. Ниже приводятся таблица, характерная, с нашей точки зрения, для различных типов внешней среды.

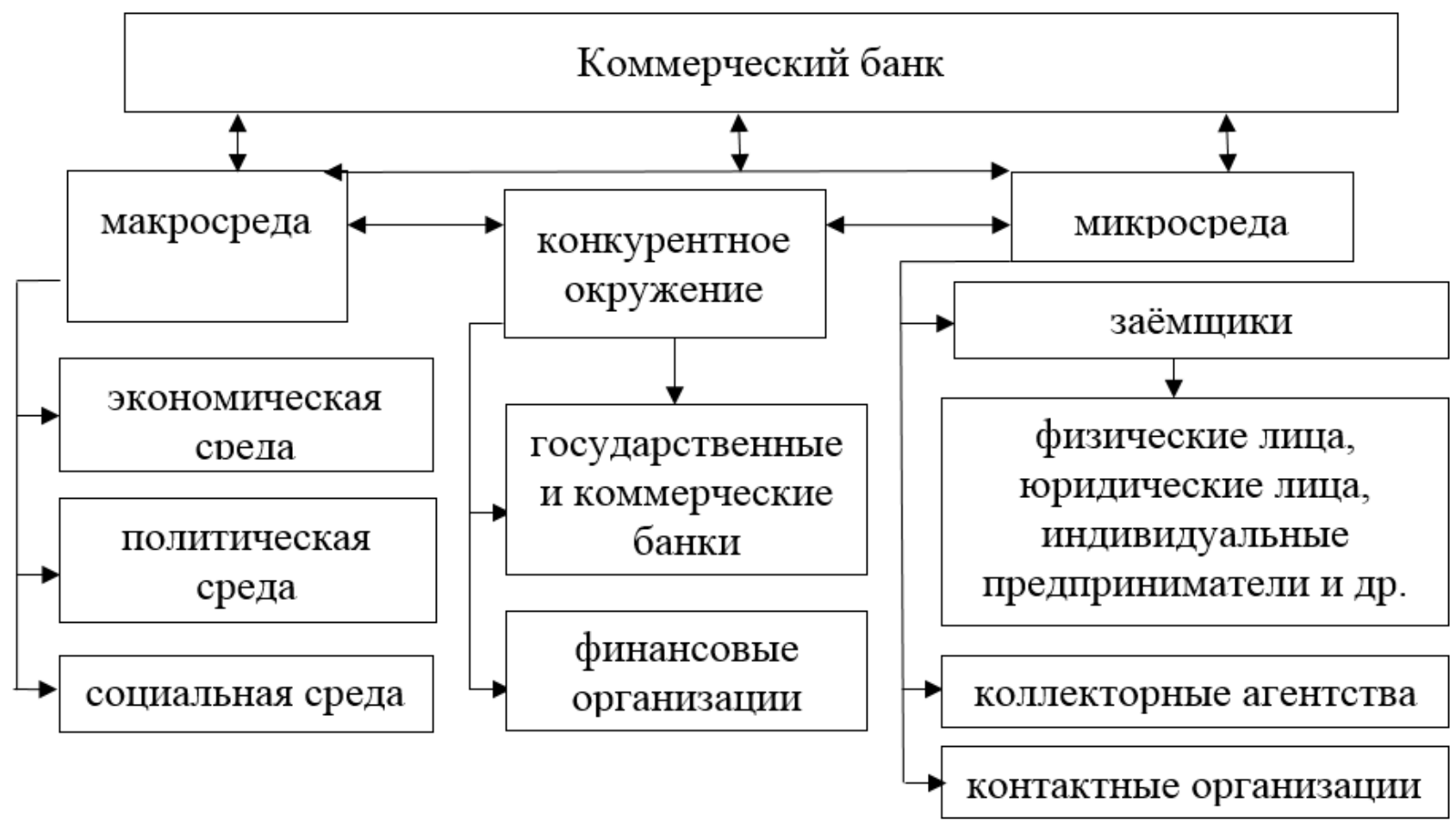

Рис. 1. Факторы внешней среды коммерческого банка 
Моделирование сбалансированного кредитного портфеля коммерческого банка в условиях ...

\begin{tabular}{|c|c|}
\hline $\begin{array}{l}\text { Основные характеристики } \\
\text { дружественной среды: } \\
\text { 1. политическая стабильность (при неста- } \\
\text { бильной ситуации ослабляется значимость } \\
\text { основной валюты, растет инфляция, тем са- } \\
\text { мым дорожают кредиты) } \\
\text { 2. умеренный темп инфляции (не более } \\
\text { 10\%) - ускоряет платежный оборот и явля- } \\
\text { ется показателем развития экономики } \\
\text { 3. низкая ключевая ставка - минимальная } \\
\text { процентная ставка, по которой Центральный } \\
\text { Банк России предоставляет кредиты коммер- } \\
\text { ческим банкам (до } 10 \% \text { ) } \\
\text { 4. абсолютный прирост реального ВВП по от- } \\
\text { ношению к предыдущему периоду } \\
\text { 5. высокий уровень качества жизни населе- }\end{array}$ & $\begin{array}{l}\text { Основные характеристики } \\
\text { недружественной среды: } \\
\text { 1. частые изменения правил и способов про- } \\
\text { ведения анализа деятельности финансовых } \\
\text { организаций } \\
\text { 2. динамика ключевой процентной ставки } \\
\text { 3. увеличение стоимости привлеченных за- } \\
\text { ёмных денежных средств банков } \\
\text { 4. низкие показатели доходности финансо- } \\
\text { вых инструментов } \\
\text { 5. кризисные явления, приводящие к массо- } \\
\text { вым закрытиям предприятий, массовым со- } \\
\text { кращениям и увольнениям } \\
\text { 6. другие природные, экологические, поли- } \\
\text { тические, экономические, технологические и } \\
\text { социальные катаклизмы, приводящие к рез- } \\
\text { ким изменениям от допустимых норм откло- } \\
\text { нения. }\end{array}$ \\
\hline
\end{tabular}

Поскольку в настоящее время у банков возникли серьёзные отношения с другими возможными источниками средств из-за кризиса, перестали даваться внешние займы. Таким образом, уменьшается количество источников заимствования денег. Мы считаем, что характерной средой, существующей в настоящее время, является именно недружественная, так как она оказывает влияние на структуру банка, элементы и связи между ними. Поскольку большинство моделей ориентируются на дружественную среду, нас интересует построение модели портфель банка в условиях недружественной среды.

Одной из ведущих проблемой банка является выбор кредитного портфеля, поскольку они должны аккуратно анализировать и решить этот вопрос для будущих клиентов. Поэтому вопрос формирования кредитного портфеля именно в условиях недружественной среды является сейчас очень важным.

\section{2. ОПТИМИЗАЦИЯ КРЕДИТНОГО ПОРТФЕЛЯ БАНКА В УСЛОВИЯХ НЕДРУЖЕСТВЕННОЙ СРЕДЫ С УЧЕТОМ РИСКОВ}

Кредитный портфель служит главным источником доходов банка и одновременно главным источником риска при размещении

активов. От структуры и качества кредитного портфеля в значительной степени зависит устойчивость банка, его репутация, финансовые результаты. Оптимальный, качественный кредитный портфель влияет на ликвидность банка и его надежность.

Вопрос формирования и анализа различных портфелей банков рассмотрен многими авторами $[4,5,6,7,8,9,10]$.

При выборе кредитного портфеля большинство авторов предлагает:

- анализ финансовой отчетности заемщика (в особенности денежный поток заемщика, его платежеспособность);

- качество финансовой отчетности заемщика (подтверждение ее достоверности и надежности);

- анализ отрасли (сферы ведения деятельности заемщика), текущее состояние, тенденции развития, прогнозы;

- уровень менеджмента заемщика;

- показатели суммарной выручки, активов и капитализации компании;

- возможность участия на финансовом рынке заимствований.

Как видим, среди этих направлений совершенно не учитывается влияние внешней среды, что мы считаем важным. Функционирование коммерческих банков в таких условиях вынуждает их разрабатывать и исполь- 
зовать в своей деятельности специфические методы, улучшающие отношения банков и их заёмщиков.

В противном случае, если среда является дружественной, коммерческим банкам предоставляется замечательная возможность для развития своих потенциалов, нахождения новых потребителей, открытие новых рынков, внедрение и разработка новых кредитных продуктов.

Ниже предлагается модель, в которой учитываются особенности внешней среды. Причем, поскольку структурно мы характеризуем внешнюю среду как дружественную и недружественную, причем важными для нас являются характеристики недружественной среды. В связи с этим, предлагается базовая модель, на основе которой мы предлагаем построить модели для разных типов клиентов. В силу того, что мы учитываем внешнюю среду, её состояние и характеристики, разным типам заёмщиков: физическим лицам, юридическим лицам, индивидуальным предпринимателям и др. по-разному ощущают на себе влияние, находясь в недружественной среде.

К тому же, в условиях высокой инфляции, а также при других условиях неопределенности, обостряется проблема определения оптимального срока проведения финансовых операций. Сильный запланированный рост цен может полностью обесценить процент кредита, что равносильно финансовым потерям банка. Во избежание подобной ситуации банки вынуждены осуществлять краткосрочные (продолжительностью менее года) финансовые операции.

Оптимизация кредитного портфеля банка предполагает выбор оптимального соотношения элементов кредитного портфеля по уровню доходности, риска для достижения целей кредитной политики коммерческого банка.

Большинство существующих моделей оптимизации рассмотрены в рамках соотношения параметров риск-доходность, а также имеют ряд ограничений и сложностей для практического применения.

\section{3. БАЗОВАЯ МОДЕЛЬ ОПТИМИЗАЦИИ КРЕДИТНОГО ПОРТФЕЛЯ БАНКА В УСЛОВИЯХ НЕДРУЖЕСТВЕННОЙ СРЕДЫ}

Основным подходом рационирования кредита является портфельный подход в формировании активов, заключающийся в максимизации полезности (максимизации доходности активов) при одновременной минимизации рисков за счет диверсификации. Снижение риска путем создания активов (диверсификации портфеля) является обычным эффектом при хранении портфеля. При этом оптимизация кредитного портфеля имеет место только в том случае, когда банк предлагает объем займа меньший, чем спрос на него.

В данной работе рассматривается деятельность коммерческого банка в условиях недружественной среды, для которого известен его капитал, набор банковских продуктов, общая сумма средств, которую он выделяет на кредитование. В связи с тем, что среда недружественная, рассматриваются только операции краткосрочного кредитования.

При рассмотрении деятельности коммерческих банков по выдаче кредитов рассматривается группа потенциальных заемщиков, подавших заявки на получение кредита. Банк со своей стороны на основе тех или иных критериев принимает решение о том, какие заявки и в каком объеме от запрашиваемой суммы стоит одобрить клиентам.

При решении задачи оптимизации кредитного портфеля банка в условиях недружественной среды выбор осуществляется по совокупности двух критериев, в качестве которых будем рассматривать функцию максимизации прибыли и функцию минимизации рисков по совокупности кредитов.

Прибыль банка понимается как средства, выражаемые в денежном эквиваленте, которые банк получает суммарно на основе своей процентной ставки по выданным кредитам:

$$
\begin{aligned}
& f_{1}(x)=\left(\sum_{k=1}^{n} r_{k} b_{k} x_{k}-\sum_{j=1}^{n} \sigma_{j} y_{j}\right) \rightarrow \max _{x}, \quad \text { (1) } \\
& n \text { - количество проектов, которые рас- } \\
& \text { сматриваются банком; }
\end{aligned}
$$


Моделирование сбалансированного кредитного портфеля коммерческого банка в условиях ...

$r_{k}$ - процентная ставка, по которой выдаётся кредит $k$-му заёмщику банком;

$b_{k}$ - объём кредита, необходимый для $k$-го проекта;

$x_{k}$ - доля от запрашиваемой суммы кредита , выдаваемого $k$-му заёмщику, $x_{k} \in[0,1]$;

$y_{j}$ - доля кредита, которую мы берём у других банков;

$\sigma_{j}$ - процентная ставка, по которой коммерческий банк покупает кредит у $j$-го банка.

Критерий минимизации рисков по совокупности рисков опишем:

$$
f_{2}(x)=\sum_{k=1}^{n} g_{k} \varphi_{k}\left(b_{k} x_{k}\right) \rightarrow \min _{x} .
$$

Для удобства осуществления дальнейших расчётов в качестве функции заимствования будем рассматривать линейую функцию:

$$
\varphi_{k}\left(b_{k} x_{k}\right)=b_{k} x_{k}
$$

$x_{k} b_{k}$ - затраты банка на кредитование $k$-го проекта;

$g_{k}$ - мера риска $k$-го проекта, оцениваемая на основе информации о клиенте, коэффициенте риска, статистических данных и т. п.

Методом оценки риска является вычисление его как стандартное отклонение:

$g_{k}=\sqrt{\sum_{i=1}^{n} p_{i}\left(\sum_{k=1}^{n} r_{k} b_{k} x_{k}-\sum_{j=1}^{n} \sigma_{j} y_{j}\right)^{2}(x)-\left(\sum_{i=1}^{n} p_{i}\left(\sum_{k=1}^{n} r_{k} b_{k} x_{k}-\sum_{j=1}^{n} \sigma_{j} y_{j}\right)(x)\right)^{2}}$,

$p_{i}$ - верояность наступления рискового события.

С увеличением объёма выдачи кредита резко увеличивается рост риска финансовой операции.

Сумма заёмных средств коммерческим банком у других банков имеет вид:

$$
f_{3}(x)=S=\sum_{j=1}^{m} \sigma_{j} y_{j} s_{j} \rightarrow \min _{\sigma},
$$

$\sigma_{j}$ - процентная ставка, по которой коммерческий банк покупает кредит у $j$-го банка;

$y_{j}$ - доля кредита, которую банк берёт у других банков;

$s_{j}$ - сумма заёмных средств у $j$-го банка.

При решении вопроса об одобрении заявки на кредит или отказе в нём, неоходимо учитывать ряд факторов:

$$
\sum_{k=1}^{n} b_{k}\left(1+r_{k}\right) x_{k} \leq R_{k}
$$

- целесообразность выдачи банком кредита;

$$
\sum_{k=1}^{n}\left(1+r_{k}\right) b_{k} x_{k} \geq\left(1-\sigma_{j}\right) y_{j}
$$

- целсообразность взятия банком кредита, так как коммерческий банк не только выдает, но и берет сам кредиты у ЦБ;

$$
0 \leq x_{k} \leq 1, \quad \forall k=\overline{1, n}
$$

- ограничение, по которому определяется доля выдаваемого кредита от запрашиваемой суммы;

$$
\sum_{k=1}^{n}\left(b_{k} x_{k}+L_{k}\right) \leq Q+\sum_{j=1}^{n}\left(1-y_{j}\right) S_{j}
$$

- проверка рациональности проведения всех операций;

$Q$ - свободные кредитные ресурсы банка;

$$
0 \leq L_{k} \leq b_{k} x_{k}
$$

- ожидаемые от операции кредитования $k$-го проекта потери;

$$
\underline{\sigma_{j}} \leq \sigma_{j} \leq \overline{\sigma_{j}}
$$

- ограничение на долю от запрашиваемой суммы, которую выдают коммерческому банку в другом банке.

В приведенной модели, обеспечивающей решение оптимизации кредитного портфеля банка в условиях недружественной среды, не учтен тот факт, что кредиты могут выдаваться разным типам заёмщиков.

Задача формирования оптимального кредитного портфеля для физических лиц коммерческого банка в условиях недружественной среды может быть представлена, опираясь на базовую модель.

При этом важно учитывать, что нужно $x_{k} \leq x_{k} \leq 1, \forall k=\overline{1, n}$ - ограничение на долю выдаваемого кредита и предлагаем для данной группы заёмщиков ввести ограничение:

$$
\sum_{k=1}^{n}\left(b_{k} x_{k}+L_{k}+A_{k}\right) \leq Q+\sum_{j=1}^{n}\left(1-y_{j}\right) S_{j}
$$

- критерий рациональности проведения операции,

где $A_{k}$ - выделяемые средства на работу коллекторных организаций.

Задача формирования оптимального кредитного портфеля для юридических лиц коммерческого банка в условиях недружественной среды может быть представлена, опираясь на базовую модель. 
При этом важно учесть $x_{k} \leq x_{k} \leq 1$, $\forall k=1, n$ - ограничение на долю выдаваемого кредита. Также нужно установить границу процентной ставки, определяемую банком $r_{k} \leq r_{k} \leq \overline{r_{k}} \forall k=\overline{1, n}$ и границу отдачи от проекта, определяемую коммерческим банком $R_{k} \leq R_{k} \leq \overline{R_{k}} \forall k=\overline{1, n}$.

Задача формирования оптимального кредитного портфеля для индивидуальных предприятий коммерческого банка в условиях недружественной среды может быть представлена, опираясь на базовую модель. При этом важно учитывать, что нужно $x_{k} \leq x_{k} \leq 1$, $\forall k=\overline{1, n}$ - ограничение на долю выдаваемого кредита. Также считаем целесообразным установить границу процентной ставки, определяемую банком -

$$
\underline{r_{k}} \leq r_{k} \leq \overline{r_{k}} \forall k=\overline{1, n} .
$$

\section{ЭКСПЕРИМЕНТАЛЬНЫЕ РАСЧЕТЫ ПО МОДЕЛИ ФОРМИРОВАНИЯ ОПТИМАЛЬНОГО ПОРТФЕЛЯ}

Для оптимизации кредитного портфеля коммерческого банка в условиях недруже-

Экспериментальный пример

\begin{tabular}{|c|c|c|c|c|c|c|c|c|c|c|}
\hline \multicolumn{11}{|c|}{ Исходные данные } \\
\hline число заявок n= & 10 & & & & & & & & & \\
\hline $\begin{array}{l}\text { мин сумма } \\
\text { кредита S0= }\end{array}$ & 200000 & & & & & & & & & \\
\hline $\begin{array}{l}\text { начальный } \\
\text { момент t0= }\end{array}$ & 1 & & & & & & & & & \\
\hline $\begin{array}{l}\text { свободные } \\
\text { средства Р0= }\end{array}$ & 10000000 & & & & & & & & & \\
\hline $\begin{array}{l}\text { последний месяц } \\
\text { планирования } \\
\mathrm{tN}=\end{array}$ & 36 & & & & & & & & & \\
\hline \multicolumn{11}{|c|}{ Данные о заявках на кредиты } \\
\hline $\begin{array}{l}\text { момент выдачи } \\
\text { средств }\end{array}$ & 1 & 1 & 1 & 2 & 1 & 2 & 1 & 1 & 2 & 1 \\
\hline номер клиента & 1 & 2 & 3 & 4 & 5 & 6 & 7 & 8 & 9 & 10 \\
\hline $\begin{array}{l}\text { запрашиваемая } \\
\text { сумма }\end{array}$ & 1500000 & 1000000 & 4000000 & 1500000 & 350000 & 1150000 & 1000000 & 750000 & 500000 & 15000000 \\
\hline $\begin{array}{l}\text { ожидаемая отда- } \\
\text { ча от проекта }\end{array}$ & 2000000 & 1800000 & 6000000 & 2300000 & 500000 & 1500000 & 1500000 & 2000000 & 900000 & 20000000 \\
\hline риск проекта & 0,3 & 0,2 & 0,25 & 0,3 & 0,2 & 0,35 & 0,15 & 0,1 & 0,3 & 0,55 \\
\hline $\begin{array}{l}\text { процентная } \\
\text { ставка }\end{array}$ & 0,2 & 0,19 & 0,18 & 0,21 & 0,23 & 0,2 & 0,22 & 0,2 & 0,24 & 0,19 \\
\hline $\begin{array}{l}\text { срок } \\
\text { кредитования }\end{array}$ & 3 & 3 & 2 & 2 & 1 & 2 & 2 & 1 & 1 & 3 \\
\hline $\begin{array}{l}\text { год, с которого } \\
\text { начин выплаты }\end{array}$ & 1 & 1 & 1 & 1 & 1 & 1 & 1 & 1 & 1 & 1 \\
\hline $\begin{array}{l}\text { число взносов } \\
\text { в год }\end{array}$ & 12 & 12 & 12 & 12 & 12 & 12 & 12 & 12 & 12 & 12 \\
\hline $\begin{array}{l}\text { вероятность } \\
\text { возврата долга }\end{array}$ & 0,8 & 0,85 & 0,8 & 0,7 & 0,85 & 0,7 & 0,9 & 0,95 & 0,8 & 0,5 \\
\hline $\begin{array}{l}\text { общее число } \\
\text { взносов }\end{array}$ & 36 & 36 & 24 & 24 & 12 & 24 & 24 & 12 & 12 & 36 \\
\hline
\end{tabular}


Моделирование сбалансированного кредитного портфеля коммерческого банка в условиях ...

\begin{tabular}{|l|r|r|r|} 
& $\begin{array}{c}\text { \% выдачи от } \\
\text { нач.суммы }\end{array}$ & $\begin{array}{c}\text { нач } . \\
\text { сумма }\end{array}$ & $\begin{array}{c}\text { выдаваемые } \\
\text { банком } \\
\text { деньги }\end{array}$ \\
\hline процент удовлетворения заявки 1 & 34,00 & 1500000 & 510004 \\
\hline процент удовлетворения заявки 2 & 100,00 & 1000000 & 1000000 \\
\hline процент удовлетворения заявки 3 & 4,21 & 4000000 & 168421 \\
\hline процент удовлетворения заявки 4 & 10,94 & 1500000 & 164103 \\
\hline процент удовлетворения заявки 5 & 50,81 & 350000 & 177844 \\
\hline процент удовлетворения заявки 6 & 14,39 & 1150000 & 165517 \\
\hline процент удовлетворения заявки 7 & 100,00 & 1000000 & 1000000 \\
\hline процент удовлетворения заявки 8 & 100,00 & 750000 & 750000 \\
\hline процент удовлетворения заявки 9 & 35,40 & 500000 & 176991 \\
\hline процент удовлетворения заявки 10 & 1,03 & 15000000 & 154689 \\
\hline
\end{tabular}

Рис. 2. Доли и суммы выдаваемых банком кредитов

ственной среды проведём расчёты для физических лиц.

Целевые функции:

$$
\begin{gathered}
f_{1}(x)=\left(\sum_{k=1}^{n} r_{k} b_{k} x_{k}-\sum_{j=1}^{n} \sigma_{j} y_{j}\right) \rightarrow \max _{x} \\
f_{2}(x)=\sum_{k=1}^{n} g_{k} b_{k} x_{k} \rightarrow \min _{x} .
\end{gathered}
$$

Ограничения:

$$
\begin{gathered}
\sum_{k=1}^{n} b_{k}\left(1+r_{k}\right) x_{k} \leq R_{k}, \underline{x_{k}} \leq x_{k} \leq \overline{x_{k}} \\
\sum_{k=1}^{n}\left(b_{k} x_{k}+L_{k}+A_{k}\right) \leq Q+\sum_{j=1}^{n}\left(1-y_{j}\right) S_{j} \\
S=\sum_{j=1}^{m} \sigma_{j} i_{j} s_{j}, \underline{\sigma_{j}} \leq \sigma_{j} \leq \overline{\sigma_{j}} .
\end{gathered}
$$

Так как представленная модель является задачей векторной оптимизации, то нахождение максимального и минимального значения целевых функций можно реализовать методом Соболя. Экспериментальный пример приведён в табл. 1 и его решение на рис. 2.

\section{ЗАКЛЮЧЕНИЕ}

В статье рассмотрены вопросы оптимизации кредитной деятельности коммерческого банка в условиях недружественной среды, в котором коммерческий банк был представлен как система. Описано формирование финансовых операций в условиях недружественной среды. Кроме того, была разработана и описана математическая модель формирования оптимального кредитного портфеля, имеющая в качестве целевых функций следующие крите- рии: максимизация прибыли, минимизация рисков и минимизация заёмных денежных средств. Были проведены экспериментальные расчеты по математическим моделям формирования оптимального портфеля для разных групп заёмщиков.

\section{СПИСОК ЛИТЕРАТУРЫ}

1. Гранберг, А. Г. Математические модели социалистической экономики: Общие принципы моделирования и статические модели нарядного хозяйства / А. Г. Гранберг. - М. : Экономика, 1978.

2. Баева, Н. Б. Основы теории систем и вычислительные схемы системного анализа / Н. Б.Баева, Д. В. Ворогушина, Е. В. Куркин. Методическое пособие для вузов. Издательско-полиграфический центр Воронежского государственного университета, 2011 - 52 с.

3. Фрейдина, Е. В. Исследование систем управления, 2009.

4. Аброкова, Л. С. Оптимизация кредитного портфеля коммерческого банка по критериям доходности, ликвидности и риска // Институты и механизмы инновационного развития: мировой опыт и российская практика / Сборник научных статей 5-й Международной научно-практической конференции. - Курск, 2015. - С. 14-18.

5. Васильева, В. А. Формирование оптимальной модели стратегии развития коммерческих банков // Бухгалтерия и банки.

6. Буренин, А. Н. Рынок ценных бумаг и производные финансовые инструменты: уч. пособие. - М. : ФКК, 1998. - 352 с. 
7. Роуз, Питер С. Банковский менеджмент; пер. с англ. со 2-го изд. - М. : Дело, 2005. $768 \mathrm{c}$.

8. Касти, Дж. Большие системы: связность, сложность, катастрофы: Пер. с англ./ Дж. Касти - М., 1982 - 19 с.

9. Трифонов, Д. А. Эволюция портфельных подходов в банковском менеджменте / Д. А. Трифонов // Финансы и кредит. - 2011. №9 (441). - С. 43-49.

10. Баева, Н. Б. Партикулярный алгоритм сопряжения интересов управляющего коммерческого банка и его собственников /

Баева Нина Борисовна - канд. экон. наук, профессор кафедры ММИО, Воронежский государственный университет

Тел.: 8(473)220-82-82

E-mail:mmio@amm.vsu.ru,baev@law.vsu.ru

Тычинина В. Н. - студентка кафедры ММИО факультета ПММ Воронежского государственного университета.

Тел.: 8 (960) 137-59-68

E-mail: tyc-vikushka95@yandex.ru
Н. Б. Баева, Ю. В. Черемушкина // Вестник Воронеж. гос. ун-та. Сер. Системный анализ и информационные технологии. - 2016. - № 4. C. 111-118.

11. Бачманова, И. А. Подходы к формированию критериев оценки кредитоспособности заемщика в условиях финансового кризиса / И. А. Бачманова, Г. Н. Чернышева // Вестник ВГТУ. - 2009. - № 6. - С. 16-19.

12. Клименчуков, А. Н. Прогнозирование финансовой устойчивости в задачах оценки долгосрочной кредитоспособности предприятий-заемщиков коммерческого банка.

Baeva N. B. - PhD in Economics, professor in Voronezh State University, Department of Mathematical Methods of Operations Research

Tel.: 8(473)220-82-82

E-mail:mmio@amm.vsu.ru

Tychinina V. N. - student, Department of Mathematical Methods of Operations Research, faculty of AMM Voronezh State University.

Tel.: 8 (960) 137-59-68

E-mail: tyc-vikushka95@yandex.ru 